\title{
Design of early warning system for reservoir flood level based on probability analysis
}

\author{
JIANG Wen-bing ${ }^{1}, \mathrm{LIU} \mathrm{Li}^{2}$ \\ \{jwb00321@sina.com¹,yueg00300@163.com² \\ (1.market director, guizhou east century science \& technology co., LTD.,Guiyang 550081,China; \\ 2.Hunan University of Finance and Economics, Changsha 410205,China;)
}

\begin{abstract}
Due to the poor accuracy of early warning results in the traditional reservoir flood level early warning system, resulting in unstable output voltage, based on this, a reservoir flood level early warning system based on probability analysis is proposed and designed. Its hardware consists of tc 401 capacitive sensor, pressure sensor $\mathrm{dx} 130$ and water level signal conditioning circuit. Its software design includes database design, water level and flow information setting, water level early warning setting. Through the system hardware design and software design, the design of the reservoir flood water level early warning system is completed. The experimental results show that compared with the traditional early warning system, the designed water level early warning system is more accurate, and the output voltage is more stable.
\end{abstract}

Keywords: Probability analysis;Reservoir flood;Water level early warning;

\section{Introduction}

In recent years, large floods have occurred in many river basins in China, which have caused great losses to the national economy and people's lives and property. How to use the latest science and technology to control the loss brought by flood to the minimum is of great practical significance. The key to flood control is to grasp the dynamic state of flood accurately and in real time. In view of these problems, the country has been committed to the research of water resources development and utilization and open source measures for a long time. Among them, flood resource utilization is an effective method. Its purpose is to effectively utilize the unusable flood resources in the flood season. This method has less damage to the ecological environment and no pollution to the green environment. Therefore, it is of great value and potential to study how to transform flood in flood season into available water resources without destroying the original flood control standard of reservoir. For the reservoir, the utilization of flood resources can not only meet the requirements of flood control, but also make full use of flood resources. In order to meet the goal of flood control and profit promotion at the same time, reservoir operation is necessary. In the flood season, when the flood comes, in most cases, in order to ensure the safety of the reservoir, direct flood discharge, 
or for the safety of the downstream, first storage and then discharge. Through reasonable reservoir operation, it can be used to cut the peak and hold back the flood, and it can also be used to store the full water to the greatest extent to make profits.

At present, there are few flood warning systems for large-scale basins in China. Most of the existing ones are wireless warning systems for small basins, and most of them are imported from abroad. The wireless early warning system sends the hydrological information to the control center through the wireless transmitter. Literature [1] puts forward the dynamic control method of reservoir operation water level in the dynamic flood prediction period. Firstly, considering that the reserved flood control capacity for the downstream reservoir has the space of overlapping use, the operation water level value in the flood period is optimized; secondly, the model is established by using the prediction and pre discharge method to calculate the upper limit value of the dynamic control area of the operation water level in the flood period; finally, the dynamic change in the flood prediction period is mainly considered, Solve the dynamic control domain based on risk analysis. According to the calculation, the operating water level of the reservoir in flood season can be increased from $347.60 \mathrm{~m}$ to $350.50 \mathrm{M}$. considering the variation interval of flood forecast period is $[3,6] \mathrm{h}$ and the interval of $0.5 \mathrm{~h}$, the dynamic control region of the operating water level in flood season is [350.50,351.40] $\mathrm{m}$. the corresponding power generation benefits can be increased by 19 million KW $• \mathrm{~h}$ to 25 million $\mathrm{KW} \cdot \mathrm{h}$ respectively. However, the accuracy of this method for water level early warning is low in the case of severe weather.

In view of the problems of the above system, this paper proposes and designs a reservoir flood level early warning system based on probability analysis.

\section{Hardware composition of early warning system of reservoir flood level based on probability analysis}

\subsection{Tc401 capacitive sensor}

The water level sensor needs to be immersed in the reservoir for a long time. The sensors made of common materials are easy to form, corrode and oxidize, which affects the liquid level detection. The inductive digital water level sensor and its system have the advantages of convenient installation and use, strong anti freezing ability, corrosion resistance and high cost performance. Now it has been widely used in the fields of hydrology, water conservancy, hydropower, information prevention engineering, national water resource management, etc. The evaluation of "inductive digital water level sensor" and its system technology by the National Hydrological Standardization Technical Committee provides a key and reliable new technology for the automatic collection and submission of the first line water level data [2]. Therefore, the system adopts the inductive digital water level sensor as the water level data 
acquisition equipment.

Tc401 capacitive digital water level sensor (commonly known as electronic water gauge) is a kind of inductive element which uses neural network circuit and mechanical method to locate accurately. The water level signal is processed by digital coding. The design idea of neural network circuit is adopted, and the position inductive element is precisely determined by the method of short-term charging of electrode plate. It has high reliability and anti-interference performance. It is the same kind of sensor in the market at present, and its technical content is also at the leading level. It is a new concept of water level sensor [3]. Its main technical features are high measurement accuracy of $0.5 \mathrm{~mm}$, stable and reliable performance, strong anti-interference ability, low energy consumption, adoption of neural simulation theory, from measurement, transformation to transmission, the whole process of digitization, large measurement range, which is suitable for the requirements of flood control and drought resistance of Jianghe reservoir, large temperature range, which is $-20 \sim+50{ }^{\circ} \mathrm{C}$; output signal can be connected with other circuits through RS232.

\subsection{Pressure sensor DX130}

Dx130 adopts the design principle of hydrostatics, with the range of $200 \mathrm{~m}$, the output voltage range of two-wire system of $0 \sim 5 \mathrm{~V}$, and the long-term stability of full degree and zero position of $0.1 \% \mathrm{FS} /$ year [4]. When the sensor is put into a certain depth of the measured liquid, the pressure formula of the sensor's liquid surface is as follows:

$$
P=p \bullet g \bullet H+P_{0}
$$

Where: $p$ is the density of the measured river water; $P$ is the pressure on the liquid surface of the sensor; $g$ is the acceleration of gravity; $P_{0}$ is the atmospheric pressure on the liquid surface; $H$ is the depth of the pressure sensor into the liquid. Because the pressure of the liquid is introduced into the positive pressure chamber of the sensor through the gas conducting stainless steel, and then the atmospheric pressure $P_{0}$ on the liquid level is connected with the negative pressure chamber of the sensor to offset the $P_{0}$ on the front of the sensor, the pressure measured by the sensor is $p \bullet g \bullet H$, and the liquid level depth $H$ can be obtained through the measured pressure $P$. When the ADC interface of the controller is connected with the voltage output of the pressure sensor, the pressure data acquisition and digital processing can be completed, and it can be converted into the water level and height 
information.

\subsection{Water Level Signal Conditioning Circuit}

Because the pressure sensor works in the low range, in order to improve the measurement accuracy, it is necessary to amplify the output voltage signal of the pressure sensor before analog-to-digital conversion [5]. AD620 is a low-cost, high-precision instrument amplifier. It only needs an external resistance $R_{3}$ to set the gain. The gain range is $1-10000$, and the power consumption is low. The maximum working current is only $1.3 \mathrm{~mA}$. The system sets the gain $\mathrm{G}=5$ (i.e. $R_{3}=12.3 \mathrm{k} \Omega$ ) [6]. The sixth pin output of AD620 is directly connected with the ADC of the controller. The signal conditioning circuit is shown in Figure 1.

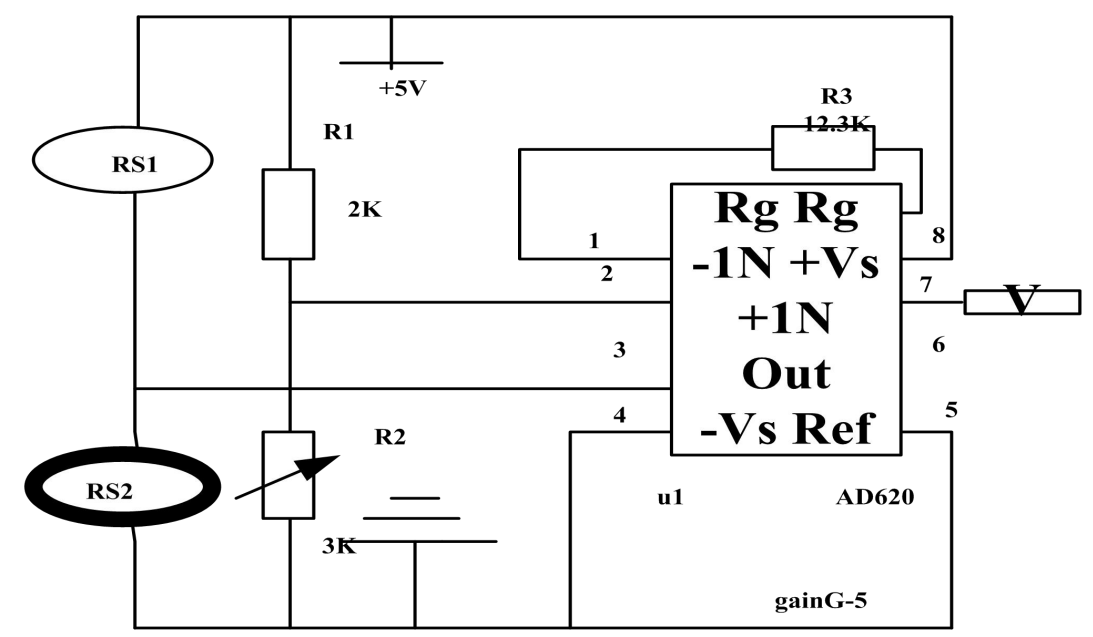

Fig. 1. Signal conditioning circuit diagram

The output voltage signal of the pressure sensor is connected to the controller through AD620 amplifier for ADC conversion, which improves the accuracy of water level measurement and meets the needs of the system.

\section{Software design of reservoir flood level early warning system based on probability analysis}

\subsection{Database design}

Under the unified data format and specification, the database is divided into basic information database and geographic information database according to the data storage mode. Oracle $10 \mathrm{~g}$ is used as database management platform. The basic information database is divided into flood database and algorithm database from the content [7]. Flood database mainly stores data of reservoir, including: 
(1) Historical hydrological, socio-economic and flood loss data, etc;

(2) Real time rainfall and water regime data, including rainfall data of meteorological station, rainfall forecast data and real-time water level and flow data of hydrological station;

(3) Model boundary, parameters, etc. These data can be automatically or manually modified to store new data. The algorithm database includes model calculation and data graphic conversion formula, which are used to support the analysis and calculation of data, as well as the mapping and transformation between data and visual elements. With the help of GIS middleware, a geographic information database is created, which mainly stores vector point data such as rainfall station, water level station, breach; vector line data such as road, linear water system, polder area and embankment; vector plane data such as administrative division, surface water system, land use and flood risk elements. Among them, the elements of flood risk are stored in grid, and the unit domain includes grid coding, maximum inundation depth, maximum inundation duration, maximum flood velocity, flood arrival time and marker domain.

The design of database mainly serves for the probability analysis of flood. The observation series $F_{y}$ (Time Series) of annual flood frequency is calculated by probability analysis method, and the expression is as follows:

$$
F_{y}=f_{y}(t)=\left[f_{y}(1), f_{y}(2), \ldots, f_{y}(n)\right]
$$

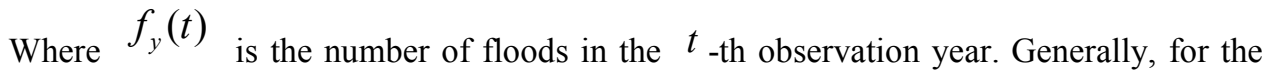
multi peak flood caused by continuous rainfall, one flood is counted in the analysis. The $F_{y}$ series is transformed as follows: if $f_{x}$ is the total number of $x$ floods per year in the observation period (i.e. the total number of observation years), then there is a series $F$ :

$$
F=\left[f_{0}, f_{1}, \ldots, f_{k}\right]
$$

That is, in year $n$, there are 0 floods in year $f_{0}, 1$ flood in year $f$ There are k floods in $f_{k}$ years. According to the calculation results, it is inferred that the probability of no more than $x$ floods per year is: 


$$
p(x \leq-)=\sum_{x=0} p(x)
$$

Let $p(-)=\max [p(0), p(1), p(2), \ldots]$, the probability of annual possible flood is $p(-) ;$ if $p(x-1)+p(x)+p(x+1)>0.6$, the probability of annual flood between $x-1$ and $x+1$ is great; the probability of annual flood greater than $x$ is:

$$
p(x>-)=1-\sum_{x=0} p(x)
$$

For different statistical intervals, if there are different $F$ series, different analysis conclusions can be obtained; for different flood peak standards, if there are different flood frequency series $F_{y}$, different flood frequency analysis conclusions can be obtained. The analysis steps are as follows:

Step 1: according to a certain peak discharge value QM, construct the annual flood frequency series $F_{y}$;

Step 2: according to 0 times, 1 time per year, the number of years of $\mathrm{K}$ floods is a series $F$;

Step 3: according to formula (4), according to the corresponding values of elements $f_{x}$ and $E(x)$ of sequence $F$, construct statistic $i_{0}^{2}$, and carry out the goodness of fit test at a given significance level $T$;

Step 4: if $F$ series conforms to Poisson distribution, calculate the probability $p(x)$ of $x$ floods per year according to formula (5), and then get the number, range and probability of possible floods per year.

\subsection{Water Level Flow Information Setting}

The water level and flow information setting module defines the maximum, minimum and relative change rate of water level and flow, compares the water level information monitored by the sensor with the warning line, and determines whether the water level of the reservoir is in a safe condition through the control chart, so as to determine whether to alarm. Among them, RS485 communication is mainly used to complete information collection and 
communication

RS485 communication is usually used as a relatively economic, high noise suppression, relatively high transmission rate, long transmission distance and wide common mode range communication mode. RS485 standard adopts data transceiver driving bus of balanced transmission and differential reception. The data line shall preferably be composed of twisted pair, and the external shield layer shall be grounded. Because 485 signal is transmitted by differential mode, that is, the voltage difference between a and B is used as signal transmission. When using twisted pair for 485 signal transmission, if there is an external interference source, the interference effect on a and B is the same, the voltage difference remains unchanged, and the interference on 485 signal is minimized. If there is shielding wire, the interference effect of external interference sources will be minimized. Some types of sensors use 485 acquisition communication interface, $65 \mathrm{lbc} 184 \mathrm{chip}$ and necessary control circuit to realize the communication between single chip computer and sensors. Through this kind of chip, the corresponding data collected by the single-chip microcomputer on the module can be exchanged with the telemetry terminal of the measuring station, and the data can be reported. $651 b c 184$ is a differential data line transceiver within the scope of sn5176 industry standard, with built-in high-energy transient noise protection device. This design features more than most of the existing devices, significantly improving the reliability of resisting the transient noise on the data synchronous transmission cable, providing a reliable and low-cost direct connection (without insulation transformer) data line interface [8], without any external components. The operating temperature of $65 \mathrm{lbc} 184$ is $-40 \mathrm{C}$ to $85 \mathrm{C}$.

Among them, the D and R interfaces are TTL standards, which can be directly connected to the UART port of single chip microcomputer for data transmission and reception, and the re and de interfaces are used to control the bus transmission mode or reception mode. In 485 communication, attention shall be paid to data confusion caused by signal reflection in communication cable, and $120 \Omega$ matching resistance shall be added to realize impedance matching [9]. Due to the complexity of some field conditions, 485 interface uses differential transmission mode, which has the ability of anti common mode interference, but it may cause high common mode voltage between nodes for some reason. When the common mode voltage is more than $+12 \mathrm{~V}$ or less than $-9 \mathrm{~V}$, the limit receiving voltage of 485 communication chip will be exceeded, which will cause 485 communication chip not to work or even burn down. At this time, 485 optical isolation repeater can be used in 485 bus to completely isolate 485 signal and power supply and eliminate the influence of common mode voltage. In order to ensure the reliable operation of single chip in extreme cases, the optical couple isolation device can be added to the interface between $651 b c 184$ and single chip. Due to the simple 
connection of 485 communication lines, only four lines a, B, VCC and GND are needed. Through the unified definition of corresponding pins of 485 communication interface of module, the 485 acquisition communication interface of telemetry terminal is specified to be consistent with it, and the unified 485 communication rate, handshake protocol, data format and encryption mode are customized. It can be realized that the front-end data acquisition of a new station is compatible, which is convenient for terminal equipment in the future According to the specific needs, select various types of sensors. In practical application, except for single point grounding of 485 bus shielding layer, it is better to use galvanized pipe to cover 485 cable when conditions permit. The galvanized pipe is well grounded, which can realize reliable shielding and lightning protection.

\subsection{Water Level Warning}

Water level early warning control indicators include water level limit control and water level change rate, as shown in Figure 2.

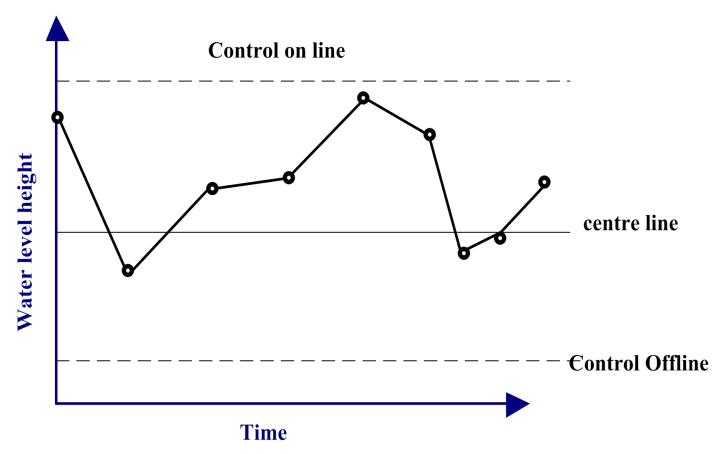

Fig. 2. Water Level Boundary Control Chart

The water level limit control chart is an effective tool for analyzing and judging the process fluctuation, which can monitor the water level data in real time. Generally, in the early stage of mine design, the upper and lower water level control limits are specified, and the historical data are continuously revised [10]. Once the water level exceeds the limit of the control chart, the alarm indicates that the water level exceeds the safety state. The monitoring of the relative change rate of water level is based on the historical data to calculate the maximum change rate of water level $\delta_{\Delta}$ in the mine, and take $\delta_{\Delta}$ as the reference to calculate the relative change rate of water level in unit time:

$$
\delta_{i}=\frac{H_{n}-H_{n-1}}{H_{n-1}\left(T_{n}-T_{n-1}\right)}
$$


Where: $H_{n}$ is the water level monitoring data collected at $\mathrm{n}$ time; $H_{n-1}$ is the water level monitoring data collected at n-1 time; $T_{n}-T_{n-1}$ is the time interval between $\mathrm{N}$ time and the previous time. When $\delta_{i}>\delta_{\Delta}$, it indicates that the relative change rate of water level exceeds the reference standard, then the system alarms.

\section{System Test Experiment}

In order to verify the performance of this system, a comparative experiment with the traditional one is designed. Through comparison, the hypothesis of the experiment is verified. The experimental environment is shown in Table 1.

Table 1 Configuration information of development environment

\begin{tabular}{|c|c|}
\hline Name & Configuration \\
\hline Operating system & Microsoft Windows XP \\
\hline Processor & $\begin{array}{c}\text { Intel }(\mathrm{R}) \text { Celeron }(\mathrm{R}) \\
2.6 \mathrm{GHz}\end{array}$ \\
\hline Internal storage & $24.0 \mathrm{~GB}$ \\
\hline Hard disk & $16.0 \mathrm{~GB}$ \\
\hline $\begin{array}{c}\text { Database } \\
\text { management } \\
\text { software }\end{array}$ & $\begin{array}{l}\text { Microsoft SQL server } \\
2010 \text { R2 }\end{array}$ \\
\hline JDK & 1.6 \\
\hline $\begin{array}{c}\text { Mathematical } \\
\text { software }\end{array}$ & MATLAB \\
\hline
\end{tabular}

\subsection{Experimental comparative analysis}


The experiment in this section will judge the advantages and disadvantages of the two systems by comparing the stability of the two systems. The experimental method is comparative experiment. The experiment verification process is completed under the control of other variables except the experimental variation.

\subsection{Experimental result}

Two systems are used to test the water level changes of seven rivers. Seven monitoring points (1-7) are set up respectively. The server of the monitoring center is always in operation state, waiting for the TCP / IP connection and communication of the water level terminal. After the water level terminal is connected with the server of the monitoring center, the green communication indicator flashes. See Table 2 and table 3 for water level monitoring data.

Table 2 Monitoring and warning data of water level under the system

\begin{tabular}{|c|c|c|c|c|c|c|}
\hline $\begin{array}{c}\text { monito } \\
\text { ring } \\
\text { site }\end{array}$ & $\begin{array}{c}\text { Output } \\
\text { voltage/ } \\
\text { V }\end{array}$ & $\begin{array}{l}\text { Water } \\
\text { level } \\
\text { height } \\
\mathrm{L} / \mathrm{m}\end{array}$ & $\begin{array}{c}\text { Upper } \\
\text { Height } \\
\text { H/m }\end{array}$ & $\begin{array}{l}\text { Lower } \\
\text { altitude } \mathrm{H} / \mathrm{m}\end{array}$ & $\begin{array}{l}\text { amplitude of } \\
\text { variationm/H }\end{array}$ & $\begin{array}{l}\text { Alarm } \\
\text { status }\end{array}$ \\
\hline 1 & 2.567 & 3.231 & 2.00 & 4.90 & +0.003 & OFF \\
\hline 2 & 1.672 & 2.104 & 1.00 & 3.40 & -0.011 & OFF \\
\hline 3 & 3.622 & 4.558 & 2.50 & 5.80 & +0.005 & OFF \\
\hline 4 & 4.250 & 5.339 & 3.50 & 6.50 & +0.023 & OFF \\
\hline 5 & 2.345 & 2.952 & 1.80 & 3.50 & -0.008 & OFF \\
\hline 6 & 2.307 & 2.904 & 1.50 & 3.60 & -0.013 & OFF \\
\hline 7 & 2.399 & 3.020 & 2.10 & 4.00 & +0.014 & OFF \\
\hline
\end{tabular}

Table 3 Water level monitoring and early warning data under traditional systems 


\begin{tabular}{|c|c|c|c|c|c|c|}
\hline $\begin{array}{c}\text { monito } \\
\text { ring } \\
\text { site }\end{array}$ & $\begin{array}{c}\text { Output } \\
\text { voltage/ } \\
\text { V }\end{array}$ & $\begin{array}{c}\text { Water } \\
\text { level } \\
\text { height } \\
\mathrm{L} / \mathrm{m}\end{array}$ & $\begin{array}{c}\text { Upper } \\
\text { Height } \\
\mathrm{H} / \mathrm{m}\end{array}$ & $\begin{array}{l}\text { Lower } \\
\text { altitude } \\
\mathrm{H} / \mathrm{m}\end{array}$ & $\begin{array}{l}\text { amplitude of } \\
\text { variationm/H }\end{array}$ & $\begin{array}{l}\text { Alarm } \\
\text { status }\end{array}$ \\
\hline 1 & 2.067 & 3.231 & 2.00 & 4.80 & +0.103 & ON \\
\hline 2 & 1.272 & 2.104 & 1.00 & 3.50 & -0.111 & OFF \\
\hline 3 & 3.022 & 4.558 & 2.50 & 5.90 & +0.105 & $\mathrm{ON}$ \\
\hline 4 & 4.050 & 5.339 & 3.50 & 6.50 & +0.023 & OFF \\
\hline 5 & 2.345 & 2.952 & 1.80 & 3.50 & -0.008 & OFF \\
\hline 6 & 1.307 & 2.904 & 1.50 & 3.70 & -0.113 & $\mathrm{ON}$ \\
\hline 7 & 2.309 & 3.020 & 2.10 & 4.00 & +0.014 & ON \\
\hline
\end{tabular}

From the contents of Table 2 and table 3, it can be seen that under the operation of the early warning system in this paper, the water level of the seven monitored rivers is within the preset safety range, that is, there is no drought or flood, nor rapid change, but the water level fluctuates slightly; and in the seven monitoring points, the output voltage of the conditioning circuit and the water level height show a basic linear relationship. Compared with the traditional early warning system, its early warning results are more accurate, and the output voltage is more stable.

In order to further verify the early warning accuracy of this system, the early warning accuracy of this system and the traditional system is compared and analyzed, and the comparison results are shown in Figure 3. 


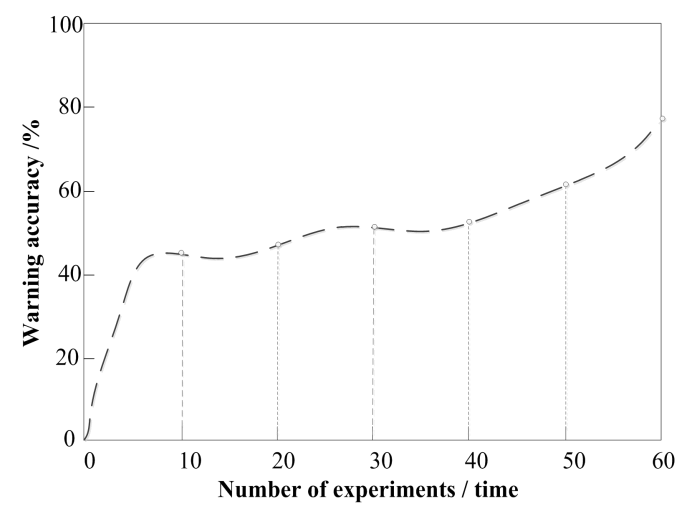

(a) The accuracy of this system

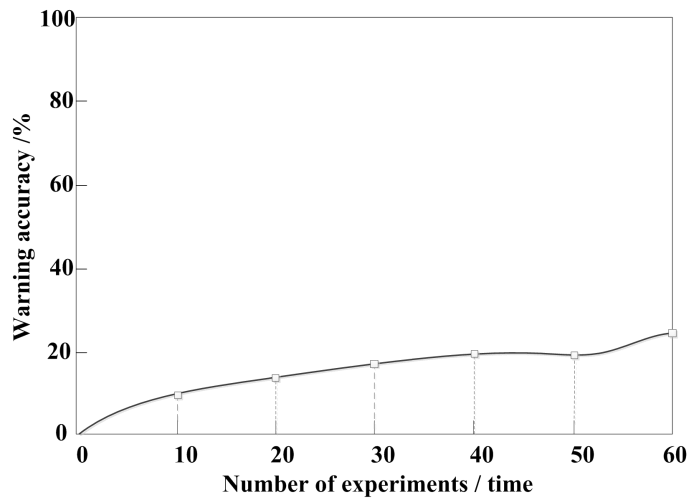

(b) Accuracy of traditional systems

Fig. 3. Comparison of the accuracy of the two systems

According to figure 3 , the accuracy of this system is within $45 \% \sim 80 \%$, up to $80 \%$, while the accuracy of traditional system is within $25 \%$, up to $25 \%$, indicating that the accuracy of this system is higher than that of traditional system.

\section{Concluding remarks}

In this paper, a reservoir flood level early-warning system based on probability analysis is designed. Through the contrast experiment with the traditional reservoir flood early-warning system, it is proved that the system designed in this paper can ensure a higher early-warning accuracy and has better stability.

\section{References}

[1] Zhang Yanke, Zhang Jiaxin, Yu Hongjie, et al. Dynamic control of reservoir operation water level considering dynamic flood prediction period. Journal of hydroelectric power generation, no. 9, pp. 64-72 (2019) 
[2] Diao Yanfang, Duan Zhen, Cheng Hui, Chen Xin, Zhang Rong, Wang Wenmin.: Design of rules for combined flood control forecasting and dispatching of reservoirs based on particle swarm. China Rural Water Conservancy and Hydropower, Vol. 33, no. 2, pp. 99-102 (2018)

[3] Zou Qiang, Hu Xiangyang, Zhou Man.: Flood Resources Utilization II: Risk Analysis and Countermeasures of Three Gorges Reservoir. People's Yangtze River, Vol. 49, no. 04, pp. 11-16+22 (2018)

[4] Xu Zhangyao, Liu Yongqiang.: Research on flood control operation risk of Baiguishan Reservoir. Water Resources Development and Management, no. 03, pp. 73-76 (2018)

[5] Duchamp.: Analysis on Flood Control Classification and Forecasting Mode and Risk of Reservoir. Agricultural Science and Technology and Information, no. 09, pp. 97-98+107 (2018)

[6] Xianjing, Shengping Gu, Leman Lin, et al.: Risk analysis of reservoir overstocking in flood season based on stochastic simulation. People's Yellow River, Vol. 40, no. 5, pp. 39-43 (2018)

[7] Allina, Guo Taiying.: Application of the method of determining flood control storage capacity based on real-time water condition information in reservoir design[J]. Hydropower Generation, Vol. 44, no. 7, pp. 646-793 (2018)

[8]Diao Yanfang, Duan Zhen, Zhang Rong, Cheng Jiaxing, Chen Xin, Dong Jie.: Risk Analysis of Joint Flood Control Forecast for Cascade Reservoirs. Hydropower Generation, Vol. 44, no. 8, pp. 82-86 (2018) [9]Li Yongqing, Yang Minhui, Ji Shengcai, et al.: Study on flood limit water level of Liujiaxia Reservoir considering flood forecast. Northwest Hydropower, no. 05, pp. 14-19 (2018)

[10]Huang Lingzhi, Li Shouyi, Si Zheng.: Risk analysis of reservoir flood limit water level dynamic control based on small rainfall forecast. Journal of Xi'an University of Technology, Vol. 34, no. 4, pp. 401-406 (2018) 